\title{
Additions to Lyophyllaceae s.l. from China
}

\author{
Jize $\mathrm{Xu}{ }^{1, *}$, Xiaodong $\mathrm{Yu}^{2}$, Nakarin Suwannarach ${ }^{3}{ }^{-}$, Yi Jiang ${ }^{1}$, Wei Zhao ${ }^{1}$ and $\mathrm{Yu} \mathrm{Li}^{4}$ \\ 1 Department of Applied Biological Science, Faculty of Agriculture, Jilin Agriculture Science and Technology \\ University, Jilin 132101, China; jy2920247902@foxmail.com (Y.J.); zhaowei0124@foxmail.com (W.Z.) \\ 2 Department of Protection and Utilization of Wild Animals and Plants, Faculty of Chinese Herbal Medicine, \\ Jilin Agricultural University, Changchun 130118, China; yxd9426@foxmail.com \\ 3 Research Center of Microbial Diversity and Sustainable Utilization, Faculty of Science, Chiang Mai University, \\ Chiang Mai 50200, Thailand; suwan.462@gmail.com \\ 4 Faculty of Plant Protection, Jilin Agricultural University, Changchun 130118, China; yuli966@163.com \\ * Correspondence: xujz802@nenu.edu.cn
}

check for updates

Citation: Xu, J.; Yu, X.; Suwannarach, N.; Jiang, Y.; Zhao, W.; Li, Y. Additions to Lyophyllaceae s.l. from China. J. Fungi 2021, 7, 1101. https:// doi.org/10.3390/jof7121101

Academic Editors: Laurent Dufossé, Samantha C. Karunarathna and Saowaluck Tibpromma

Received: 3 November 2021 Accepted: 15 December 2021 Published: 20 December 2021

Publisher's Note: MDPI stays neutral with regard to jurisdictional claims in published maps and institutional affiliations.

Copyright: (c) 2021 by the authors. Licensee MDPI, Basel, Switzerland. This article is an open access article distributed under the terms and conditions of the Creative Commons Attribution (CC BY) license (https:// creativecommons.org/licenses/by/ $4.0 /)$.

\begin{abstract}
Four new species, viz. Calocybe coacta, C. fulvipes, C. vinacea and Clitolyophyllum umbilicatum, are described in northern China. Comparisons are made of macro- and micromorphological features among the new species and closely related species within the genus. The new species feature unique morphological characteristics that separate them from the previously described species. Calocybe coacta is characterized by medium- to large-sized basidiocarps, greyish cream, felty pileus and non-cellular epicutis. The key characteristics of $C$. fulvipes are rose-brown to greyish-brown pileus, stone-brown stipe and non-cellular epicutis. The unique morphological characteristics of C. vinacea that distinguish it from its closely related species are pastel red to dull-red pileus and stipe surface with densely white pruina. The main characteristics of Clitolyophyllum umbilicatum are deeply depressed dark orange to light-brown pileus, central stipe and subglobose-ellipsoid spores. Phylogenetic analyses based on the ITS and 28S regions indicated that the four new species are distinct and monophyletic. Full descriptions, color images, illustrations and a phylogenetic tree that show the placement of the four new species are provided. A key to the Calocybe species reported from China is also given.
\end{abstract}

Keywords: Calocybe; lyophylloid species; morphological characteristics; phylogenetic analyses; taxonomy

\section{Introduction}

Lyophyllaceae Jülich was suggested by recent molecular phylogenetic analyses to be a putative wider concept that includes several lineages that seem more distantly related, and the generic concepts should be reconsidered [1-5]. Several new genera established in the past ten years were expected to reorganize the system, viz. Calocybella Vizzini, Consiglio \& Setti, Clitolyophyllum E. Sesli, Vizzini \& Contu, Myochromella V. Hofst., Clémençon, Moncalvo \& Redhead, Sagaranella V. Hofst., Clémençon, Moncalvo \& Redhead, Sphagnurus Redhead \& V. Hofst., Tephrocybella Picillo, Vizzini \& Contu and Tricholyophyllum Qing Cai, G. Kost \& Zhu L. Yang [2,6-10]; however, a few of them show a poor species diversity worldwide. Clitolyophyllum was discovered in 2016, a Turkish species fruiting on the dead bark of Picea orientalis. It is mainly characterized by fan-shaped, translucent-striate pileus; decurrent lamellae; lateral, cylindrical to flattened stipe; smooth, inamyloid spores; nonsiderophilous basidia and irregular pileipellis [7]. Until now, Clitolyophyllum has remained monotypic, and so far, it is known to have only one species in Turkey.

Calocybe Kühner ex Donk, typified by C. gambosa (Fr.) Donk, was a traditional genus of Lyophyllaceae first discovered by Kühner [11]. Singer's concept of Calocybe included characteristics such as mostly bright-colored pileus, vacuolar pigment, small spores, pileipellis of a cutis or cellular [12]. The taxonomic status of Calocybe used to be confused with 
Lyophyllum P. Karst. and Rugosomyces Raithelh. $[13,14]$. Several recent molecular phylogenetic analyses have confirmed Calocybe as an independent genus with the merging of Rugosomyces [2,3,15-17]. At least 57 species can be assigned to Calocybe according to $\mathrm{Xu}$ et al. [17]; however, the molecular phylogenetic relationships among members of the Calocybe were inconsistent with the morphological classification made by Singer [12]. Therefore, the infrageneric classification of Calocybe remains in a redelineated position.

The species of Lyophyllaceae are distributed all over the world [12,18,19]. Recently, many new species and new recorded species have also been reported in China [10,15-17,20-25]. To date, only 14 Calocybe species have been reported in China: Calocybe aurantiaca X.D. Yu \& Jia J. Li, C. badiofloccosa J. Z. Xu \& Yu Li, C. carnea (Bull.) Donk, C. convexa X.D. Yu \& Jia J. Li, C. chrysenteron (Bull.) Singer, C. decurrens J. Z. Xu \& Yu Li, C. decolorata X.D. Yu \& Jia J. Li, C. erminea J. Z. Xu \& Yu Li, C. gambosa (Fr.) Donk, C. gangraenosa (Fr.) V. Hofst., Moncalvo, Redhead \& Vilgalys [=Lyophyllum leucophaeatum (P. Karst.) P. Karst.; Index Fungorum], C. hebelomoides (Ew. Gerhardt) Læssøe \& J.H. Petersen [=Lyophyllum hebelomoides (Ew. Gerhardt) Consiglio \& Contu; Index Fungorum], C. ionides (Bull.) Donk, C. naucoria (Murrill) Singer and C. obscurissima (A. Pearson) M.M. Moser [15-17,24-27]. However, Clitolyophyllum has not been reported in China.

During the survey of macrofungi in northern China, four unique species of the family Lyophyllaceae were newly discovered in the forests dominated by Acer sp., Quercus mongolica or Picea crassifolia. The aim of this study was to describe four new lyophylloid species: Calocybe fulvipes, C. coacta, C. vinacea and Clitolyophyllum umbilicatum based on morphological features and molecular data. In addition, we explored the species diversity of Calocybe based on the previous studies and compiled the information on the Calocybe species reported in China.

\section{Materials and Methods}

\subsection{Specimen Sampling}

All the specimens were collected in 2012-2021 from northern China. The collected samples were dried overnight using an electric drying oven at $45^{\circ} \mathrm{C}$ and deposited in the Herbarium Mycology of Jilin Agricultural Science and Technology University (HMJU).

\subsection{Morphological Observation}

The macromorphological descriptions were recorded in the field, and images of the basidiocarps were taken in the field with a Canon 80D camera. The Kornerup and Wanscher color description was used to describe color terms, where a specific code is assigned to an observed color [28]. Micromorphology of the specimens was studied with the help of an Olympus BX 53 (Tokyo, Japan) light microscope at $40 \times, 100 \times, 400 \times, 600 \times$ and $1000 \times$ magnifications (measurements were performed under oil immersion at $1000 \times$ magnification). Sections of the dried specimens were mounted in $3 \% \mathrm{KOH}, 1 \%$ Congo red and Melzer's reagent for observations. Cotton blue and iron acetocarmine solutions were used to highlight the siderophilous granulation in the basidia. Factor $Q$ is the value of its length divided by width and $\mathrm{Qm}$ is the mean of the $\mathrm{Q}$ values. The procedure for scanning electron microscopy (SEM) followed that of Xu et al. [29], and an FEI Quanta 200FE-SEM (JEOL Ltd., Akishima, Japan) was used at an accelerating voltage of 5-10 kV.

\subsection{DNA Extraction, PCR, Sequencing and Phylogenetic Analyses}

Total genomic DNA was extracted using an M5 Fungal Genomic DNA Kit (Mei5 Biotechnology Co., Ltd., Beijing, China) and an Ezup Column Fungi Genomic DNA Purification Kit (Sangon Biotech Co., Ltd., Shanghai, China) according to the manufacturers' instructions. For the polymerase chain reaction (PCR) amplification, primers ITS1 and ITS4 [30] were used for the ITS region while primer LR0R was paired with LR6 and LR7 in order to obtain sequences for the $28 \mathrm{~S}$ region [31]. The reactions were performed with the following program: initial denaturation at $94^{\circ} \mathrm{C}$ for $5 \mathrm{~min}$ (ITS) or $4 \mathrm{~min}$ (28S), 33 cycles at $94{ }^{\circ} \mathrm{C}$ for $30 \mathrm{~s}, 46{ }^{\circ} \mathrm{C}(28 \mathrm{~S})$ or $53{ }^{\circ} \mathrm{C}$ (ITS) for $30 \mathrm{~s}$ or $45 \mathrm{~s}(28 \mathrm{~S})$, and $72{ }^{\circ} \mathrm{C}$ for $30 \mathrm{~s}$ (ITS) or $40 \mathrm{~s}$ 
(28S), and for terminal elongation, the reaction batches were incubated at $72{ }^{\circ} \mathrm{C}$ for $10 \mathrm{~min}$. The PCR products were examined on a 1\% agarose gel detected by a JY 600 electrophoresis apparatus (Beijing JUNYI Electrophoresis Co., Ltd., Beijing, China) and then sent to BGI Co., Ltd. (Beijing, China) for sequencing.

\subsection{Phylogenetic Analyses}

The newly generated sequences were compared with the representative ITS and 28S sequences retrieved from GenBank. Species of other genera in Lyophyllaceae were also included according to former phylogenetic studies [2,3,7,10,32], while Entoloma sericeonitidum and Entoloma sericeum were included as the outgroup. Alignments were generated for the ITS and 28S datasets using MAFFT 7.0 [33] under default conditions and then edited with MEGA 7.0 [34]. The selection of the best-fitting model was completed by ModelFinder [35] based on the Bayesian information criterion (BIC) to provide a substitution model. The $\mathrm{GTR}+\mathrm{F}+\mathrm{I}+\mathrm{G} 4$ model was chosen for this purpose. Maximum likelihood (ML) and Bayesian inference (BI) analyses were used to infer the phylogenetic position of the new species. ML estimation was performed through IQ-TREE [36] with 1000 bootstrap replicates [37]. BI phylogeny using Markov chain Monte Carlo (MCMC) methods was carried out with MrBayes 3.2.2 [38]. Two parallel runs were conducted with one cold and four heated chains each for 1,000,000 generations, starting with a random tree. Trees were saved every 1000 generations resulting in broad sampling of 10,001 trees. The initial burn-in was set to $25 \%$ (2500 trees). A 50\% majority-rule consensus cladogram was computed from the remaining trees to obtain estimates for Bayesian posterior probabilities. The significance threshold was set to $>0.95$ for Bayesian posterior probability (PP) and $>70 \%$ for ML bootstrap proportions (BP). All the sequences used in this study are listed in Table 1.

Table 1. Taxa names, accession numbers and the corresponding GenBank accession numbers of the taxa used in the molecular analyses. The newly generated sequences are in black bold.

\begin{tabular}{|c|c|c|c|}
\hline \multirow{2}{*}{ Species } & \multirow{2}{*}{ Collection } & \multicolumn{2}{|c|}{ GenBank Accession Numbers } \\
\hline & & ITS & $28 S$ \\
\hline Arthromyces matolae & TJB9912 & EU708338 & EU708335 \\
\hline Arthromyces matolae & DLC04-170 & EU708339 & EU708336 \\
\hline Asterophora lycoperdoides & CBS170.86 & AF357037 & AF223190 \\
\hline Asterophora parasitica & CBS683.82 & AF357038 & AF223191 \\
\hline Atractosporocybe inornata & TO AV201012d & KJ680993 & KJ681046 \\
\hline Blastosporella zonata & TJB8371 & EU708340 & EU708337 \\
\hline Calocybe aurantiaca & SYAU-FUNGI-005 & KU528828 & KU528833 \\
\hline Calocybe aurantiaca & SYAU:FUNGI 006 & NR156304 & NG058937 \\
\hline Calocybe badiofloccosa & HMJU00099 & OK649912 & OK649882 \\
\hline Calocybe badiofloccosa & HMJU00100 & MN172331 & MN172333 \\
\hline Calocybe buxea & EB 20140228 & KP885633 & KP885625 \\
\hline Calocybe carnea & CBS552.50 & AF357028 & AF223178 \\
\hline Calocybe cf. graveolens & FR2014043 & KP192609 & - \\
\hline Calocybe chrysenteron & AMB 17092 & KP885639 & KP885628 \\
\hline Calocybe chrysenteron var.cerina & L 05-87 & KP885640 & KP885629 \\
\hline Calocybe coata & HMJU269 & OK649907 & OL687156 \\
\hline Calocybe convexa & SYAU-FUNGI-007 & KU528826 & KU528830 \\
\hline Calocybe convexa & SYAU:FUNGI 008 & NR156303 & NG058936 \\
\hline Calocybe cyanea & RVPR10June97 & - & AF261400 \\
\hline Calocybe decolorata & SYAU-FUNGI-003 & KU528824 & KU528834 \\
\hline Calocybe decolorata & SYAU:FUNGI 004 & NR_156302 & NG_058938 \\
\hline Calocybe decurrens & HMJU 382 & MT080028 & MW'- 444857 \\
\hline Calocybe decurrens & HMJU 383 & OK649913 & OK649883 \\
\hline Calocybe erminea & HMJU00097 & OK649911 & OK649881 \\
\hline Calocybe erminea & HMJU00098 & MN172332 & MN172334 \\
\hline Calocybe fulvipes & HMJU 317 & MT071590 & OK649878 \\
\hline Calocybe fulvipes & HMJU 319 & MW406907 & OK649879 \\
\hline Calocybe fulvipes & HMJU 3027 & OK649910 & OK649880 \\
\hline Calocybe gambosa & HC78/64 & AF357027 & AF223177 \\
\hline Calocybe gangraenosa & Hae251.97 & AF357032 & AF223202 \\
\hline Calocybe hypoxantha & EC 20140117 & KP885634 & KP885626 \\
\hline
\end{tabular}


Table 1. Cont.

\begin{tabular}{|c|c|c|c|}
\hline \multirow{2}{*}{ Species } & \multirow{2}{*}{ Collection } & \multicolumn{2}{|c|}{ GenBank Accession Numbers } \\
\hline & & ITS & $28 \mathrm{~S}$ \\
\hline Calocybe hypoxantha & EC 20140228 & KР885635 & - \\
\hline Calocybe ionides & HC77/133 & AF357029 & AF223179 \\
\hline Calocybe naucoria & AMB 17094 & KP885642 & KP885630 \\
\hline Calocybe naucoria & HC80/103 & AF357030 & AF223180 \\
\hline Calocybe obscurissima & HC79/181 & AF357031 & AF223181 \\
\hline Calocybe onychina & CAON-RH19-563 & MW084664 & MW084704 \\
\hline Calocybe persicolor & HC80/99 & AF357026 & AF223176 \\
\hline Calocybe vinacea & HMJU5135 & OK649908 & OK649876 \\
\hline Calocybe vinacea & HMJU5160 & OK649909 & OK649877 \\
\hline Calocybella dominicana & JBSD 126507 & KY363575 & KY363577 \\
\hline Calocybella pudica & AMB 15994 & KP858000 & KP858005 \\
\hline Clitocybe subditopoda & AFTOL-ID 533 & DQ202269 & AY691889 \\
\hline Clitocybe subditopoda & OSC 112607 & EU697244 & EU852807 \\
\hline Clitolyophyllum akcaabatense & KATO Fungi 3184 & KT934393 & KT934394 \\
\hline Clitolyophyllum umbilicatum & HMJU 262 & OK649905 & OK649873 \\
\hline Clitolyophyllum umbilicatum & HMJU 1558 & OK649906 & OK649874 \\
\hline Entoloma sericeonitidum & TB7144 & EF421108 & AF261315 \\
\hline Gerhardtia borealis & AMB 15993 & KР858004 & KP858009 \\
\hline Gerhardtia citrinolobata & JBSD 126508 & KY363576 & KY363578 \\
\hline Gerhardtia highlandensis & PBM2806 (CUW) & GU734744 & EF535275 \\
\hline Gerhardtia sp. & HC01/025 & EF421103 & EF421091 \\
\hline Hypsizygus ulmarius & DUKE-JM/HW & EF421105 & AF042584 \\
\hline Leucocybe candicans & AFTOL-ID 541 & DQ202268 & AY 645055 \\
\hline Leucocybe connata & DUKE-JM90c & EF421104 & AF042590 \\
\hline Lyophyllum caerulescens & $\mathrm{HC} 80 / 140$ & AF357052 & AF223209 \\
\hline Lyophyllum decastes & JM87/16(T1) & AF357059 & AF042583 \\
\hline Lyophyllum favrei & IE-BSG-HC96ср4 & EF421102 & AF223184 \\
\hline Lyophyllum favrei & Hae234.97 & AF357034 & AF223183 \\
\hline Lyophyllum leucophaeatum & Hae251.97 & AF357032 & AF223202 \\
\hline Lyophyllum ochraceum & BSI94.cp1 & AF357033 & AF223185 \\
\hline Lyophyllum semitale & $\mathrm{HC} 85 / 13$ & AF357049 & AF042581 \\
\hline Lyophyllum sykosporum & IFO30978 & AF357050 & AF223208 \\
\hline Myochromella boudieri & BSI96/84 & AF357047 & DQ825430 \\
\hline Myochromella inolens & CBS330.85 & AF357045 & AF223201 \\
\hline Nolanea sericea & VHAs03/02 & DQ367430 & DQ367423 \\
\hline Ossicaulis aff. lignatilis & KAD14 & MG663236 & MT237454 \\
\hline Ossicaulis lignatilis & D604 & DQ825426 & AF261397 \\
\hline Ossicaulis yunnanensis & IJ152 & KY411962 & KY411960 \\
\hline Ossicaulis yunnanensis & $\mathrm{IH} 26$ & KY411961 & KY411959 \\
\hline Rugosomyces obscurissimus & FR2014101 & KР192650 & - \\
\hline Rugosomyces pseudoflammulus & FR2014054 & KР192579 & - \\
\hline Rhizocybe vermicularis & AH33078 & KJ681032 & - \\
\hline Sagaranella gibberosa & CBS328.50 & AF357041 & AF223197 \\
\hline Sagaranella tylicolor & BSI92/245 & AF357040 & AF223195 \\
\hline Sphagnurus palustris & CBS717.87 & AF357044 & AF223200 \\
\hline Tephrocybe ambusta & CBS452.87 & AF357057 & AF223216 \\
\hline Tephrocybe anthracophila & HC79/132 & AF357055 & AF223212 \\
\hline Tephrocybe atrata & CBS709.87 & AF357053 & AF223210 \\
\hline Tephrocybe rancida & CBS204.47 & AF357025 & AF223203 \\
\hline Tephrocybella constrictospora & TO HG3329 & MF614962 & MF614963 \\
\hline Tephrocybella griseonigrescens & TO:HG 21112014 & NR137975 & KR476785 \\
\hline Tephroderma fuscopallens & EM4789-12 & KJ701326 & KJ701332 \\
\hline Tephroderma fuscopallens & LUG18989 & KJ701327 & KJ701333 \\
\hline Termitomyces microcarpus & PRU3900 & AF357023 & AF042587 \\
\hline Termitomyces sp. & AFTOL-ID 1384 & DQ494698 & DQ110875 \\
\hline Tricholomella constricta & $\mathrm{HC} 84 / 75$ & AF357036 & AF223188 \\
\hline Tricholyophyllum brunneum & HKAS107494 & MT705717 & MT734655 \\
\hline
\end{tabular}

\section{Results}

\subsection{Phylogenetic Analyses}

The combined dataset included 146 sequences, of which 118 were retrieved from GenBank. In the BLAST results, Calocybe coacta sequences showed $92.79 \%$ similarity to C. gangraenosa (=Lyophyllum leucophaeatum) (KP192606) with 97\% query coverage for ITS and $99.89 \%$ similarity to $C$. decurrens (MW444857) with 100\% query coverage for 28S; C. fulvipes 
sequences showed $94.96 \%$ similarity to C. carnea (AF357028) with $79 \%$ query coverage for ITS and $99.93 \%$ similarity to C. decurrens (MW444857) with 100\% query coverage for 28S; C. vinacea sequences showed $95.73 \%$ similarity to C. carnea (AF357028) with $86 \%$ query coverage for ITS and $99.70 \%$ similarity to C. decurrens (MW444857) with 100\% query coverage for 28S; Clitolyophyllum umbilicatum sequences showed $93.17 \%$ similarity to Clitolyophyllum akcaabatense (MN661004) with 97\% query coverage for ITS and $98.68 \%$ similarity to Clitocybe candicans (AY645055) with $95 \%$ query coverage for 28S. Both BI and ML approaches resulted in the same tree topology; as such, only the ML tree is shown, with Bayesian PP values (left) and MLBP values (right) provided near each node (Figure 1). Nodes were annotated if supported by $>0.95$ Bayesian PP (left) or $>70 \% \mathrm{ML}$ BP (right) values according to Vizzini et al. and Cai et al. $[6,10]$. In the resulting tree, Clitolyophyllum umbilicatum formed a clade with Clitolyophyllum akcaabatense Sesli, Vizzini \& Contu. The clade was clustered within the core Lyophyllaceae s.l. and occupied an independent phylogenetic position which related to Tephroderma fuscopallens Musumeci \& Contu. In Calocybe, five clades could be recognized corresponding with former phylogenetic studies $[15,17]$. Calocybe fulvipes and C. vinacea grouped in clade II related to C. carnea (Bull.) Donk, C. persicolor (Fr.) Singer and Calocybe decurrens, C. coacta grouped in clade IV and C. gangraenosa (=Lyophyllum leucophaeatum) appeared to be the most closely related species.

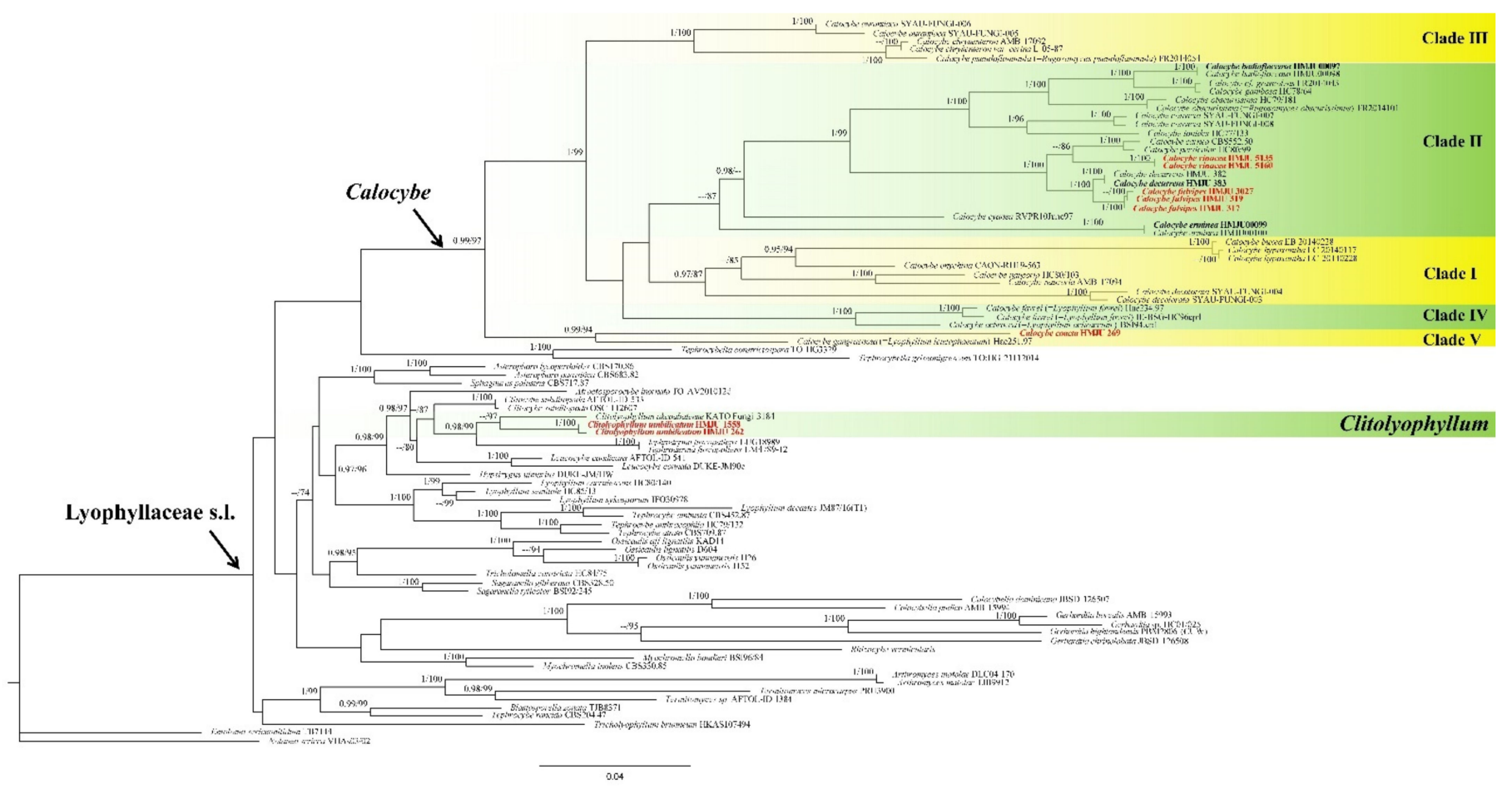

Figure 1. ML and Bayesian phylogenetic analysis of Lyophyllaceae s.l. based on ITS $+28 \mathrm{~S}$ sequences. The newly generated sequences in black bold and the new species are indicated in red bold.

\subsection{Taxonomy}

Calocybe coacta J.Z. Xu \& Yu Li, sp. nov. (Figure 2).

Mycobank number: MB842022.

Diagnosis: Calocybe coacta is distinct from C. gangraenosa (=Lyophyllum leucophaeatum), the most morphologically and molecularly similar species within Calocybe, in having a greyish cream felty pileus and smooth spores.

Holotype: China, Liaoning Prov., Fuxin City, Haitang Mountain, on soil, under mixed forests dominated by Acer sp., 1 September 2012, J.Z. Xu (HMJU 269, holotype).

Etymology: "coacta"—felted; refers to the felty pileus. 
Description: Tricholomatoid basidiocarps. Pileus $60-115 \mathrm{~mm}$ in diam., convex at first, soon becoming planoconvex, with many or few round pits 2-6 mm wide, surface greyishcream to greyish-yellow (5B3-4B3), felty, not smooth, dry, margin incurved, sometimes irregular. Lamellae adnate to decurrent, crowded, 3-5.5 mm wide, concolorous with the pileus or slightly darker towards to the pileus, unchanging when injured, with numerous tiers of lamellulae, edges entire. Stipe 40-58 $\mathrm{mm}$ long and 20-30 mm wide, broad at the base, concolorous with the pileus, surface longitudinally striate. Context white, odor and taste not distinct.

Basidiospores (5.7) 6.1-7.8 × (2.7) 2.9-3.9 $\mu \mathrm{m}, \mathrm{Q}=(1.75)$ 1.80-2.40 (2.45), $\mathrm{Qm}=2.05$, oblong, smooth, cyanophilous, inamyloid. Basidia (24.1) 25.7-31.7 × 6.3-7.4 (7.6) $\mu \mathrm{m}$, clavate, tetrasporic, sterigmata up to $4.8 \mu \mathrm{m}$ long, with numerous internal siderophilous granules. Hymenial cystidia 20.0-24.4 × 4.9-6.8 (7.2), fusiform. Hymenophoral trama regular, subparallel, hyaline, hyphae cylindrical, thin-walled, 4-18 $\mu \mathrm{m}$ wide, not pigmented. Pileipellis a cutis of subparallel, dense, branched cylindrical hyphae, hyphae, 3.3-9.8 $\mu \mathrm{m}$ in diam., thin-walled, not pigmented. Stipitipellis composed of parallel, cylindrical, repent, hyaline hyphae, 6.0-17.8 $\mu \mathrm{m}$ wide. Clamp connections present.
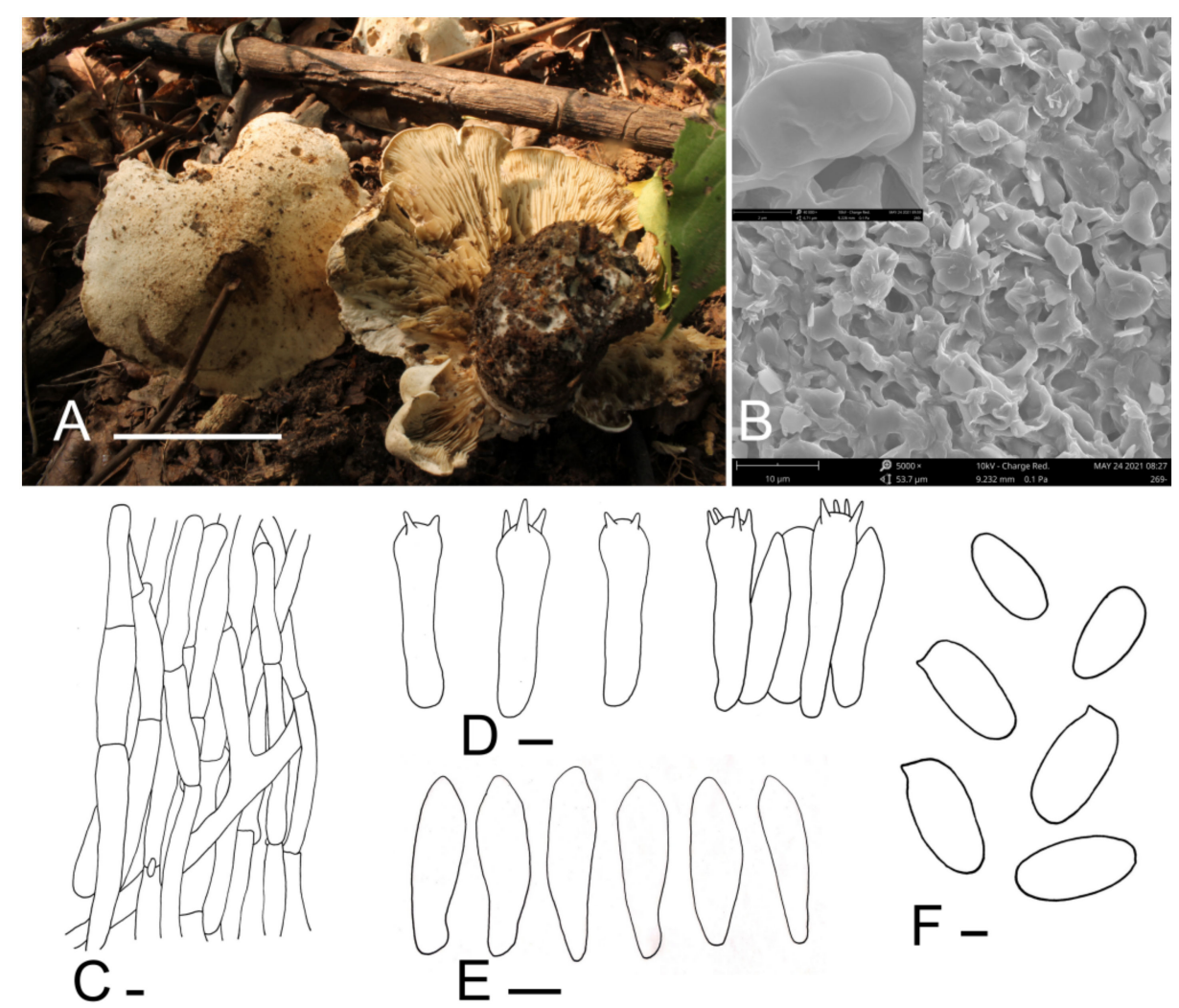

Figure 2. Calocybe coacta (HMJU 269, holotype). (A) Habitat and basidiocarps; (B) SEM images of basidiospores; (C) pileipellis; (D) basidia; (E) hymenial cystidia; (F) basidiospores. Scale bar: (A) 5 $\mathrm{cm} ;(\mathbf{C}, \mathbf{E}) 5 \mu \mathrm{m} ;$ (F) $1 \mu \mathrm{m}$.

Habitat: Scattered on soil under mixed forests dominated by Acer sp.

Known distribution: Known only from northeastern China.

Notes: Calocybe coacta is morphologically similar to species with medium- to largesized basidiocarps, greyish-cream pileus and non-cellular epicutis in sect. Calocybe such as C. pilosella Floriani \& Vizzini, C. gambosa (Fr.) Donk and C. vasilievae (Singer) Singer [12]. Calocybe coacta differs from $C$. pilosella because of its adnate to decurrent lamellae, oblong spores, and C. pilosella has emarginate lamellae and ovoid to ellipsoid spores. Moreover, C. coacta has fusiform cystidia, which are absent in C. pilosella [39]. C. gambosa and C. vasilievae are distinguished from $C$. coacta by the smooth pileus; the pileus of $C$. coacta is 
felty; also, emarginate lamellae are present in C. gambosa $[26,27,40]$. Furthermore, C. coacta and $C$. vasilievae can be differentiated by the size of the stipe $(40-58 \times 20-30 \mathrm{~mm}$ in C. coacta and 30-50 × 8-10 $\mathrm{mm}$ in C. vasilievae) [41].

Calocybe fulvipes J. Z. Xu \& Yu Li, sp. nov. (Figure 3).

Mycobank number: MB842023.

Diagnosis: Small to medium basidiocarps, rose-brown to greyish-brown pileus center, adnexed to slightly emarginate lamellae, stone-brown stipe and the absence of cystidia make it unique among the Calocybe species.

Holotype: China, Jilin Prov., Jilin City, Guoding Moutain, on soil, under mixed forests dominated by Acer sp. and Quercus mongolica, 9 September 2019, J.Z. Xu (HMJU 317, holotype).

Etymology: "fulvipes" refers to the stone-brown stipe.

Description: Pileus 55-70 mm in diam., planoconcave or almost plane with or without a small umbo in the center, center rose-brown to greyish-brown (9D4, 9E3), becoming paler towards the margin, margin brownish-orange (6B3) to brownish-beige (6B2), surface dry, glabrous. Lamellae adnexed to slightly emarginate, almost crowded, $1.4-1.8 \mathrm{~mm}$ wide, white, greyish-orange (5B3) when bruised, with numerous tiers of lamellulae, edges entire. Stipe 50-75 $\mathrm{mm}$ long and 6-11 $\mathrm{mm}$ wide, cylindrical, slightly broad at the base, solid; surface stone-brown (7F5) to deep mahogany (7F8), fibrillose. Context white, odor and taste not distinct.

Basidiospores (4.5) 5.0-6.4 (7.5) × (2.1) 2.4-3.2 (4.3) $\mu \mathrm{m}, \mathrm{Q}=(1.67) 1.78-2.42$ (2.75), $\mathrm{Qm}=2.12$, oblong, sometimes bacilliform, smooth, cyanophilous, inamyloid. Basidia 14.7$20.2(20.6) \times(3.4)$ 4.7-6.1 (6.5) $\mu \mathrm{m}$, clavate, sometimes cylindrical, tetrasporic, sterigmata up to $3 \mu \mathrm{m}$ long, with numerous internal siderophilous granules. Cystidia absent. Hymenophoral trama regular, parallel, hyaline, hyphae cylindrical, 3-13 $\mu \mathrm{m}$ wide, thin-walled, not pigmented. Pileipellis a cutis of subparallel, dense, repent, cylindrical hyphae, 3.5-12.9 $\mu \mathrm{m}$ in diam., thin-walled, not pigmented. Stipitipellis composed of subparallel, cylindrical, repent, hyaline hyphae, 5.0-14.2 $\mu \mathrm{m}$ wide. Clamp connections present.

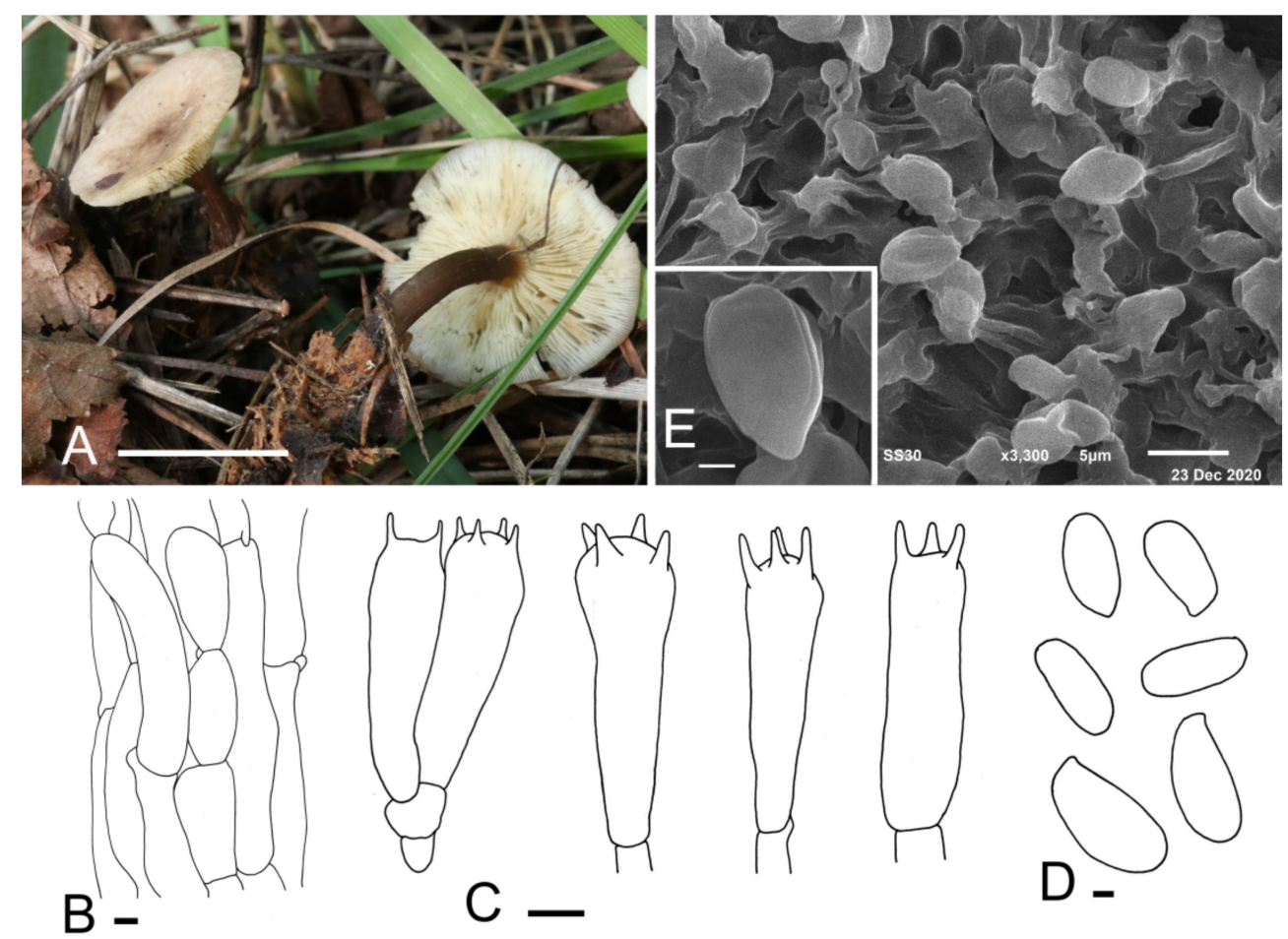

Figure 3. Calocybe fulvipes (HMJU 317, holotype). (A) Habitat and basidiocarps; (B) pileipellis; (C) basidia; (D) basidiospores; (E) SEM images of basidiospores. Scale bar: (A) $5 \mathrm{~cm}$; (B,C) $5 \mu \mathrm{m}$; $(\mathrm{D}, \mathrm{E}) 1 \mu \mathrm{m}$. 
Habitat: Scattered on soil under mixed forests dominated by Acer sp. and Quercus mongolica.

Known distribution: So far, only known from northeastern China.

Additional material examined: China, Jilin Prov., Yanbian Korean Autonomous Prefecture, Longjing City, 16 September 2019, J.Z. Xu (HMJU 319); Jilin City, Guoding Mountain, 5 September 2013, J.Z. Xu (HMJU 2912, HMJU 3027).

Note: The key characteristics of $C$. fulvipes are its rose-brown to greyish-brown pileus, stone-brown stipe and non-cellular epicutis, which suggest that it should be in sect. Carneoviolaceae [12]. In that section, C. carnea resembles C. fulvipes due to the light carneous pileus and similar spore size. They can be differentiated by the color of stipe and the shape of the pileus. Calocybe carnea produces a convex pileus and a white stipe, while $C$. fulvipes has a plane pileus and a brown stipe [41].

Calocybe vinacea J. Z. Xu \& Yu Li, sp. nov. (Figure 4).

Mycobank number: MB842024.

Diagnosis: Characterized by its slender tricholomatoid basidiocarps of small to medium size, pastel red to dull-red pileus with densely white appendages, adnate to subdecurrent lamellae, stipe with densely mycelium-like appendages, oblong spores and clavate or subcapitate terminal elements in the pileipellis.

Holotype: China, Jilin Prov., Baishan City, Manjiang Town, on the humus in broadleaved forests, 1 September 2021, J.Z. Xu (HMJU 5135, holotype).

Etymology: "vinacea" - wine-colored, refers to the dull-red pileus.

Description: Basidiocarps slenderly tricholomatoid. Pileus $15-55 \mathrm{~mm}$ in diam., convex or hemispherical at first, then planoconvex, with a broad obtuse umbo, surface pastel red to dull-red (10A5-10C3), slightly hygrophanous, not striate, with densely white pruina becoming sparser at maturity; margin incurved, even, entire when young, sometimes irregular, wavy, undulating, strongly and deeply plurilobed to subpetaloid at mature stages. Lamellae adnate to subdecurrent, crowded, 0.5-3 mm wide, yellowish-white (4A2), with numerous tiers of lamellulae; edges entire or slightly eroded. Stipe $26-57 \mathrm{~mm}$ long and $6-17 \mathrm{~mm}$ wide, central, cylindrical, subequal, surface white (10A1), longitudinally striate, with appendages the same as the pileus, subtended by abundant and thin whitish rhizoids at the base. Context thin, fleshy.

Basidiospores (3.5) 4.2-5.3 (5.6) $\times 2.2-2.8 \mu \mathrm{m}, \mathrm{Q}=(1.39)$ 1.55-2.24 (2.35), $\mathrm{Qm}=1.93$, oblong, smooth, cyanophilous, inamyloid. Basidia (15.0) 16.3-23.0 (23.8) $\times$ (3.6) 4.0-5.8 $\mu \mathrm{m}$, clavate, tetrasporic, with numerous internal siderophilous granules. Hymenial cystidia not observed. Hymenophoral trama regular composed of parallel, cylindrical, hyaline, thinwalled, 2-11 $\mu \mathrm{m}$ wide hyphae. Pileipellis a cutis of subparallel, cylindrical, hyaline hyphae, hyphae 2-14 $\mu \mathrm{m}$ wide, thin-walled; terminal elements, (18.4) 20.6-31.5 (38.9) $\times$ (5.0) 5.4-8.2 (8.9) $\mu \mathrm{m}$, clavate, subcapitate, thin-walled, hyaline. Stipitipellis regular consisting of parallel, cylindrical, hyaline hyphae, hyphae $2-11 \mu \mathrm{m}$ wide, thin-walled. Clamp connections present.

Habitat: Scattered on the humus in broad-leaved forests.

Known distribution: Known only from northeastern China.

Additional material examined: China, Jilin Prov., Baishan City, Manjiang Town, on the humus in broad-leaved forests, 1 September 2021, J.Z. Xu (HMJU 5160).

Notes: The pastel red to dull-red pileus, smooth spores and pileipellis of the cutis type suggests that $C$. vinacea should be in sect. Carneoviolaceae [12]. The unique pileus color, deeply plurilobed to subpetaloid margin in age, longitudinally striate stipe with densely white pruina overall and clavate or subcapitate terminal elements in the pileipellis apparently separate it from other species within the section. C. rubra Rick ex Redhead \& Singer and C. bipigmentata Singer which used to be placed in sect. Pseudoflammulae by Singer resemble $C$. vinacea in the pileus color; however, $C$. rubra differs in a carnea-red and narrow stipe of only $3 \mathrm{~mm}$ wide [42,43]. C. bipigmentata is mainly different from C. vinacea in having ochraceous lamellae, a glabrous, ochraceous stipe and narrow-fusoid cheilocystidia, which lacking in C. vinacea [44]. 


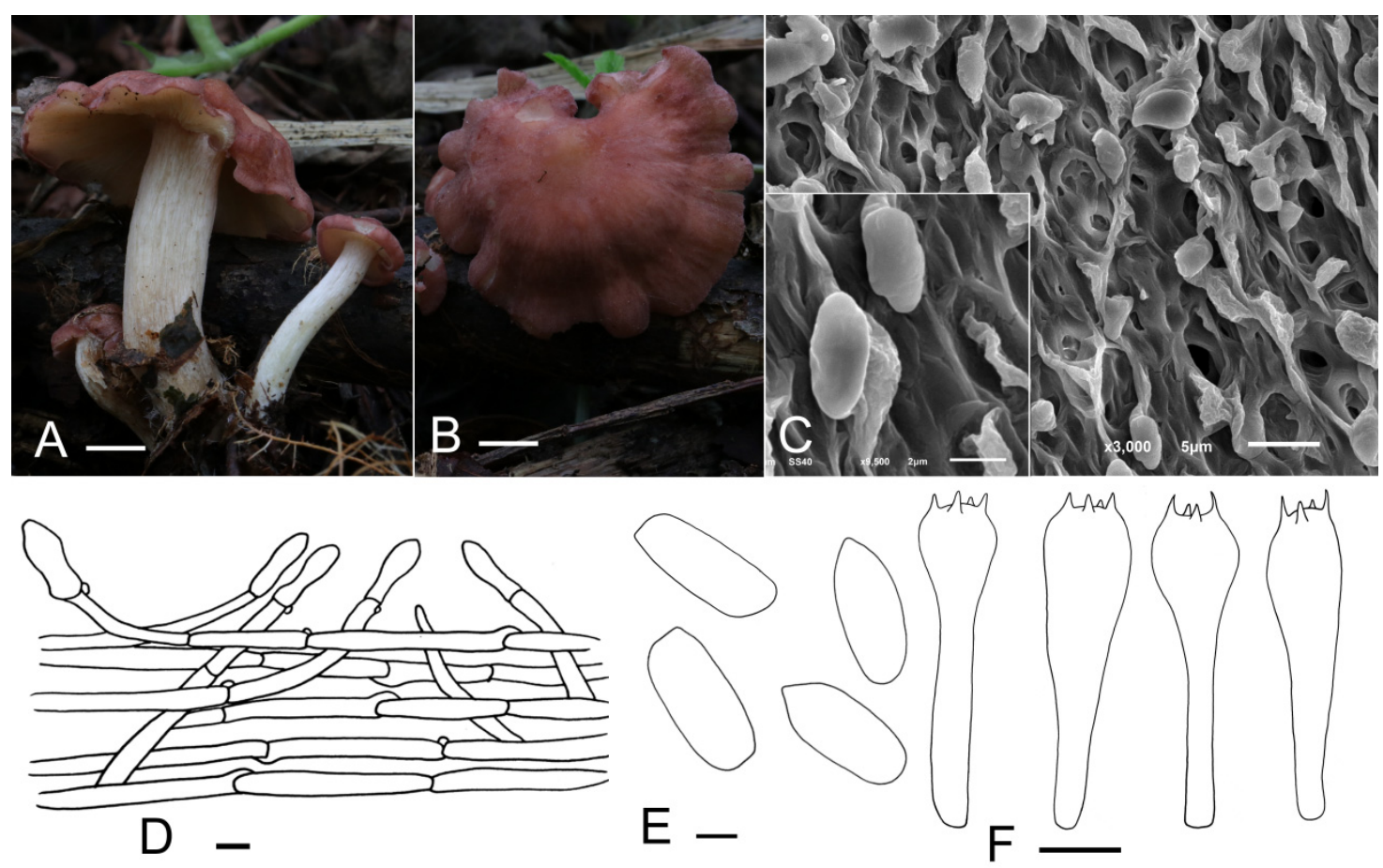

Figure 4. Calocybe vinacea (HMJU 5135, holotype). (A,B) Habitat and basidiocarps; (C) SEM images of basidiospores; (D) pileipellis; (E) basidiospores; (F) basidia. Scale bar: (A,B) $1 \mathrm{~cm}$; (D) $10 \mu \mathrm{m}$; (E) $1 \mu \mathrm{m}$; (F) $5 \mu \mathrm{m}$.

Clitolyophyllum umbilicatum J. Z. Xu \& Yu Li, sp. nov. (Figure 5).

Mycobank number: MB842025.

Diagnosis: It is distinguished by the omphalioid or clitocyboid habit, umbilicate pileus, central stipe, smooth, inamyloid spores and subregular pileipellis.

Holotype: China, Gansu Prov., Zhangye City, Yugur Autonomous County of Sunan, Xishui Forest Farm, in the moss, under a forest dominated by Picea crassifolia, 10 August 2018, J.Z. Xu (HMJU 262, holotype).

Etymology: "umbilicatum" refers to the umbilicate pileus.

Description: Basidiocarps omphalioid or clitocyboid. Pileus 38-62 $\mathrm{mm}$ in diam., deeply depressed, dark orange to light brown (6B6-6D7), surface smooth, slightly hygrophanous; margin incurved to straight, white to greyish-orange (6A1-6B3), radially striate, slightly wavy with age. Lamellae decurrent, moderately crowded, 4-8 $\mathrm{mm}$ wide, thin, color slightly paler than the pileus (6B2-6B4), with numerous tiers of lamellulae, edges entire, even. Stipe 52-74 mm long and 5-9 mm wide, central, cylindrical or slightly compressed, equal or slightly tapering towards the apex, hollow, surface orange-grey to light brown (6B2-6D7), longitudinally striate, often with white appendages at the apex. Context thin, fleshy, slightly paler than the pileus.

Basidiospores (4.9) 5.3-8.0 (8.8) × (3.8) 4.0-5.7 $\mu \mathrm{m}, \mathrm{Q}=(1.14) 1.20-1.54$ (1.62), $\mathrm{Qm}=1.36$, subglobose-ellipsoid, smooth, inamyloid, cyanophilic. Basidia (20.0) 21.2-28.7 (29.0) $\times(5.1)$ 5.7-8.0 (8.3) $\mu \mathrm{m}$, narrowly clavate or clavate, $2-4$ spores, siderophilous granulations not obviously observed. Hymenophoral trama regular, consisting of subcylindrical, subinflated, thin-walled, 2.2-18.1 $\mu \mathrm{m}$ wide hyphae. Hymenial cystidia not observed. Pileipellis a cutis composed of subparallel, dense, cylindrical hyphae, hyphae 2.1-18.9 $\mu \mathrm{m}$ wide, thin-walled; terminal elements, (30.2) 33.8-50.6 (54.5) × (3.0) 3.6-5.7 (7.4) $\mu \mathrm{m}$, irregular, cylindrical, flexuose, thin-walled, pileocystidia-like. Stipitipellis made up of regularly parallel, cylindrical, hyaline hyphae, hyphae 2.3-16.4 $\mu \mathrm{m}$ wide. Clamp connections present.

Habitat: Scattered in the moss under a forest dominated by Picea crassifolia.

Known distribution: Known only from northwestern China. 
Additional material examined: China, Gansu Prov., Zhangye City, Yugur Autonomous County of Sunan, Xishui Forest Farm, in the moss under a forest dominated by Picea crassifolia, 10 August 2018, J.Z. Xu (HMJU 1558).

Note: Clitolyophyllum akcaabatense shares a few characteristics with C. umbilicatum such as the similarly sized pileus, decurrent lamellae, hollow stipe, similar smooth, inamyloid basidiospores, non-siderophilous basidia, absence of hymenial cystidia and the pileocystidia-like terminal elements in the pileipellis. However, C. akcaabatense is distinguished from C. umbilicatum in having a fan-shaped pileus with a small depression where it is connected to the stipe, a lateral stipe that tapers towards the base, with lower two thirds covered with a typical white to creamy, woolly mycelium [7]. Microscopically, C. akcaabatense is mainly different from C. umbilicatum in having ellipsoid-fusoid, sublacrymoid spores with $\mathrm{Q}=1.58-1.78$ [spores subglobose-ellipsoid, $\mathrm{Q}=(1.14) 1.20-1.54$ (1.62) in C. umbilicatum] and irregular pileipellis [7].

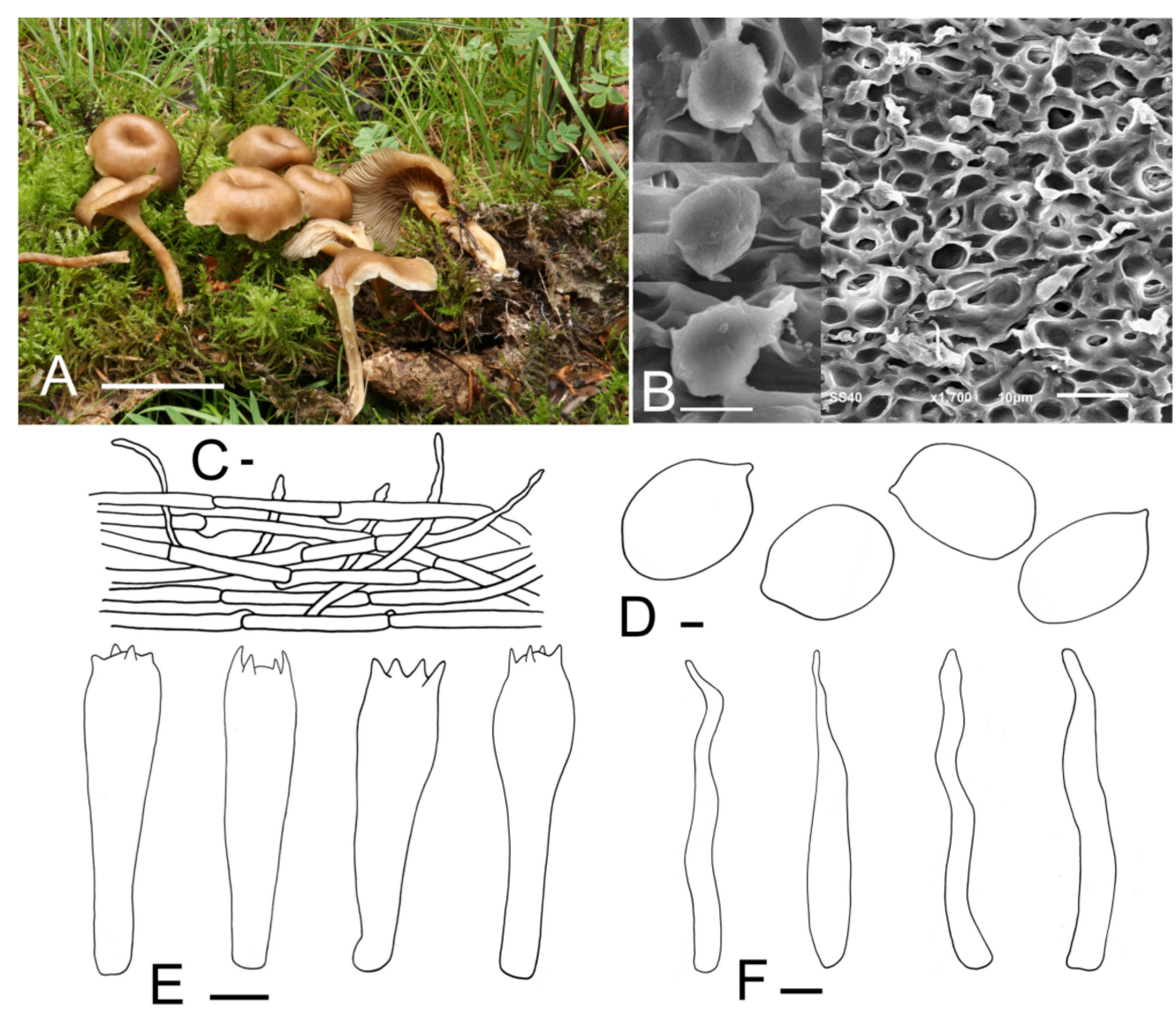

Figure 5. Clitolyophyllum umbilicata (HMJU 262, holotype). (A) Habitat and basidiocarps; (B) SEM images of basidiospores; (C) pileipellis; (D) basidiospores; (E) basidia; (F) terminal elements in the pileipellis. Scale bar: (A) $5 \mathrm{~cm}$; (C) $10 \mu \mathrm{m}$; (D) $1 \mu \mathrm{m}$; (B,E,F) $5 \mu \mathrm{m}$.

\section{Discussion}

In the combined ITS and LSU phylogenetic analysis (Figure 1), Lyophyllaceae s.l. appear to be polyphyletic, which is consistent with previous studies $[2,3,5,10]$. The new species described in this study occupy independent positions. Clitolyophyllum umbilicatum formed a distinct clade with Clitolyophyllum akcaabatense, but morphologically, C. akcaabatense can be distinguished from C. umbilicatum by a fan-shaped pileus with a small depression, a lateral stipe that tapers to the base and ellipsoid-fusoid, sublacrymoid spores. Furthermore, Clitolyophyllum umbilicatum grows on the moss under forests dominated by Picea crassifolia, while C. akcaabatense grows on the dead bark of Picea orientalis together with mosses. 
Phylogenetically, Calocybe fulvipes clusters in a single clade sister to a clade of C. decurrens; however, they can be easily distinguished from one another by morphology. Calocybe fulvipes has a glabrous pileus, adnexed to slightly emarginate lamellae and a stone-brown stipe which does not change with age while $C$. decurrens has a carneous, slightly pruinose pileus, decurrent lamellae and a pastel stipe that turns brownish-red or greyish-brown when mature [17]. In addition, C. fulvipes grows on soil under mixed forests dominated by Acer sp. and Quercus mongolica, while C. decurrens grows on soil under mixed forests dominated by Salix sp. Calocybe vinacea is a group in clade II and is related to C. carnea and C. persicolor. The combination of the pastel red to dull-red pileus with densely spaced white pruina and white stipe with the same surface are unique to $C$. vinacea, and are unknown in other Calocybe species. Calocybe coacta is related to C. gangraenosa (Lyophyllum leucophaeatum), while $C$. coacta is distinct from $C$. gangraenosa in having a greyish-cream felty pileus and smooth spores, while $C$. gangraenosa produces a whitish to brownish-grey (when matured) pileus and spores ornamented with warts $[27,43]$.

Calocybe buxea (Maire) Raithelh. and C. hypoxantha (Joss. \& Riousset) Bon. were placed in clade I in single-gene analysis based on ITS and $28 \mathrm{~S}$ by Li et al. but were not present in the combined analysis [15]. In the present study, they were located in clade II. Hence, the location of the two species may require more material, mainly, both taxa sampled and other gene fragments, to determine.

In our research on the species of Calocybe in China, we failed to get the type specimens and corresponding morphological description of $C$. hebelomoides, and could not confirm the existence of this species in China. The taxonomic treatments of $C$. hebelomoides from China should be performed on the basis of additional detailed morphological investigations in later studies. A key for the other 16 Calocybe species reported from China is provided below:

1. Basidiocarps medium to large, pileus usually more than $6 \mathrm{~cm}$ diam, stipe more than $3.5 \mathrm{~cm}$ long

$1^{\prime}$. Basidiocarps small, pileus usually less than $6 \mathrm{~cm}$ diam, stipe less than $3.5 \mathrm{~cm}$ long

2. Lamellae sinuate

2'. Lamellae not sinuate

3. Pileus bruised blue, spore non-smooth

3 '. Pileus bruised unchanged, spore smooth

4. Lamellae adnexed to slightly emarginate, lamellae less than $3 \mathrm{~mm}$ width

$4^{\prime}$. Lamellae decurrent, lamellae more than $3 \mathrm{~mm}$ width

5. Stipe base broad, lamellae greyish orange when bruised, cystidia present

5 '. Stipe base narrow, lamellae unchanged when bruised, cystidia absent

6. Lamellae bruised blue

6 . Lamellae unchanged when bruised

7. Stipe base with white pubescence

7 . Stipe base without white pubescence

8. Lamellae decurrent, pileus left plane and slightly depressed

8 '. Lamellae not decurrent, pileus left convex

9. Pileus margin regular, stipe apex with whitish pruina

$9^{\prime}$. Pileus margin flexuous, stipe apex without whitish pruina

10. Lamellae sinuate, pileus with purple tones.

$10^{\prime}$. Lamellae adnate, pileus without purple tones

11. Lamellae white

$11^{\prime}$. Lamellae not white

12. Pileus yellow, pileus surface fibrillose, basidiospores less than $5 \mu \mathrm{m}$ length

12 . Pileus pink, pileus surface smooth, basidiospores more than $5 \mu \mathrm{m}$ length

13. Lamellae with yellow tones

$13^{\prime}$. Lamellae with taupe tones

14. Pileus diam more than $5.5 \mathrm{~cm}$, Stipe with pruinose at apex

$14^{\prime}$. Pileus diam less than $5.5 \mathrm{~cm}$, Stipe without pruinose at apex

15. Pileus surface pastel red to dullred, basidiospores more than $4 \mu \mathrm{m}$ length

$15^{\prime}$. Pileus surface reddish yellow, basidiospores less than $4 \mu \mathrm{m}$ length

2
6
3
4
C. gangraenosa
C. gambosa
C. fulvipes
5
C. coacta
C. decurrens
C. decolorata
7
C. badiofloccosa
8
9
10
C. erminea
C. aurantiaca
C. ionides
11
12
13
C. convexa
C. carnea
14
C. obscurissima
C. chrysenteron
15
C. vinacea
C. naucoria

Author Contributions: Conceptualization, J.X.; sample collection, J.X. and X.Y.; experiment, J.X. and X.Y.; software, X.Y. and Y.J.; formal analysis, J.X. and N.S.; morphological analysis, W.Z. and J.X.; writing - original draft preparation, J.X. and X.Y.; writing-review and editing, N.S. and Y.L.; constructive discussions, J.X. All authors have read and agreed to the published version of the manuscript. 
Funding: This research was funded by The Science and Technology Department of Jilin Province (20200402086NC) and The Doctoral Scientific Research Foundation of Jilin Agriculture Science and Technology University.

Institutional Review Board Statement: Not applicable.

Informed Consent Statement: Not applicable.

Conflicts of Interest: The authors declare no conflict of interest.

\section{References}

1. Hofstetter, V.; Clémençon, H.; Vilgalys, R.; Moncalvo, J.-M. Phylogenetic analyses of the Lyophylleae (Agaricales, Basidiomycota) based on nuclear and mitochondrial rDNA sequences. Mycol. Res. 2002, 106, 104-1059. [CrossRef]

2. Hofstetter, V.; Redhead, S.A.; Kauff, F.; Moncalvo, J.-M.; Matheny, P.B.; Vilgalys, R. Taxonomic Revision and Examination of Ecological Transitions of the Lyophyllaceae (Basidiomycota, Agaricales) Based on a Multigene Phylogeny. Cryptogam. Mycol. 2014, 35, 399-425. [CrossRef]

3. Bellanger, J.-M.; Moreau, P.-A.; Corriol, G.; Bidaud, A.; Chalange, R.; Dudova, Z.; Richard, F. Plunging hands into the mushroom jar: A phylogenetic framework for Lyophyllaceae (Agaricales, Basidiomycota). Genetica 2015, 143, 169-194. [CrossRef]

4. Dentinger, B.T.M.; Gaya, E.; O’Brien, H.; Suz, L.M.; Lachlan, R.; Díaz-Valderrama, J.R.; Koch, R.A.; Aime, M.C. Tales from the crypt: Genome mining from fungarium specimens improves resolution of the mushroom tree of life. Biol. J. Linn. Soc. 2016, 117, 11-32. [CrossRef]

5. Alvarado, P.; Moreau, P.-A.; Dima, B.; Vizzini, A.; Consiglio, G.; Moreno, G.; Setti, L.; Kekki, T.; Huhtinen, S.; Liimatainen, K.; et al. Pseudoclitocybaceae fam. nov. (Agaricales, Tricholomatineae), a new arrangement at family, genus and species level. Fungal Divers. 2018, 90, 109-133. [CrossRef]

6. Vizzini, A.; Consiglio, G.; Setti, L.; Ercole, E. Calocybella, a new genus for Rugosomyces pudicus (Agaricales, Lyophyllaceae) and emendation of the genus Gerhardtia. IMA Fungus 2015, 6, 1-11. [CrossRef] [PubMed]

7. Sesli, E.; Vizzini, A.; Ercole, E.; Contu, M. Clitolyophyllum akcaabatense gen. nov., sp. nov. (Agaricales, Tricholomatineae); a new fan-shaped clitocyboid agaric from Turkey. Botany 2016, 94, 73-80. [CrossRef]

8. Redhead, S.A. Nomenclatural novelties. Index Fungorum 2014, 202, 1.

9. Crous, P.W.; Wingfield, M.J.; Guarro, J.; Hernández-Restrepo, M.; Sutton, D.A.; Acharya, K.; Barber, P.A.; Boekhout, T.; Dimitrov, R.A.; Dueñas, M.; et al. Fungal Planet description sheets: 320-370. Persoonia 2015, 34, 167-266. [CrossRef]

10. Cai, Q.; LvLi, Y.-J.; Kost, G.; Yang, Z.-L. Tricholyophyllum brunneum gen. et. sp. nov. with bacilliform basidiospores in the family Lyophyllaceae. Mycosystema 2020, 39, 1-13.

11. Kühner, R. Utilisation du carmin acétique dans la classification des agarics leucosporés. Bulletin Mensuel Societe Linneenne Lyon 1938, 7, 204-212. [CrossRef]

12. Singer, R. The Agaricales in Modern Taxonomy, 4th ed.; Koeltz Scientific Books: Koenigstein, Germany, $1986 ;$ p. 981.

13. Kühner, R.; Romagnesi, H. Flore Analytique des Champignons Supérieurs (Agarics, Boelts, Chanterelles); Masson: Paris, France, 1953; pp. $1-556$.

14. Arnolds, E. A confusing duo: Calocybe cerina and Callistosporium pinicola (Agaricales). Acta Mycol. 2013, 41, 29-40. [CrossRef]

15. Li, J.-J.; Wu, S.-Y.; Yu, X.-D.; Zhang, S.-B.; Cao, D.-X. Three new species of Calocybe (Agaricales, Basidiomycota) from northeastern China are supported by morphological and molecular data. Mycologia 2017, 109, 55-63. [CrossRef] [PubMed]

16. Xu, J.; Yu, X.; Zhang, C.; Li, Y. Two new species of Calocybe (Lyophyllaceae) from northeast China. Phytotaxa 2019, 425, 219-232. [CrossRef]

17. Xu, J.; Yu, X.; Zhang, C.; Li, Y. Morphological characteristics and phylogenetic analyses revealed a new Calocybe (Lyophyllaceae, Basidiomycota) species from northeast China. Phytotaxa 2021, 490, 203-210. [CrossRef]

18. Consiglio, G.; Contu, M. Il genere Lyophyllum P. Karst. emend. Kühner, in Italia. Rivista di Micologia 2002, 45, 99-181.

19. Kalamees, K. Palearctic Lyophyllaceae (Tricholomataceae) in northern and eastern Europe and Asia. Scr. Mycol. 2004, 18, 3-134.

20. Yang, S.-D.; Huang, H.-Y.; Zhao, J.; Zeng, N.-K.; Tang, L.-P. Ossicaulis yunnanensis sp. nov. (Lyophyllaceae, Agaricales) from southwestern China. Mycoscience 2018, 59, 33-37. [CrossRef]

21. Ding, Y.; Tian, E.; Alvarado, P. A new species of Rhizocybe (tricholomatoid clade, Agaricales) from Yunnan, China. Phytotaxa 2017, 328, 267. [CrossRef]

22. Mu, M.; Huang, H.-Y.; Huang, T.; Yang, S.-D.; Tang, L.-P. Gerhardtia yunnanensis (Agaricales, Lyophyllaceae), a new species from southwest China. Phytotaxa 2021, 484, 217-226. [CrossRef]

23. Li, T.; Deng, W.; Wang, C.; Song, B. Gerhardtia sinensis (Agaricales, Lyophyllaceae), a new species and a newly recorded genus for China. Phytotaxa 2017, 332, 172. [CrossRef]

24. Zhang, J.W.; Ma, S.Y.; Qi, L.L.; Li, Y. Macrofungal flora diversity in Liangshui Nature Reserve, Heilongjiang Province. J. Fungal Res. 2017, 15, 170-176.

25. Wang, Y. Study on the Diversity of Macrofungi in Tanggou Greenstone Valley National Forest Park, Liaoning Province; Jilin Agricultural University: Changchun, China, 2019; pp. 1-79.

26. Mao, X.L. The Macrofungi in China; Henan Science Technology Press: Zhengzhou, China, 2000; pp. 1-719. 
27. Li, Y.; Li, T.H.; Yang, Z.L.; Bau, T.; Dai, Y.C. Atlas of Chinese Macrofungal Resources; Central China Farmers Publishing House: Zhengzhou, China, 2015; pp. 1-1351.

28. Kornerup, A.; Wanscher, J.H.K. The Methuen Handbook of Colour; Eyre Methuen: London, UK, 1978; pp. 1-252.

29. Xu, J.; Yu, X.; Lu, M.; Hu, J.; Moodley, O.; Zhang, C.; Gong, L.; Li, Y. Phylogenetic Analyses of Some Melanoleuca Species (Agaricales, Tricholomataceae) in Northern China, With Descriptions of Two New Species and the Identification of Seven Species as a First Record. Front. Microbiol. 2019, 10, 2167. [CrossRef] [PubMed]

30. White, T.; Bruns, T.; Lee, S.; Taylor, J. Amplification and Direct Sequencing of Fungal Ribosomal RNA Genes for Phylogenetics. In PCR Protocols; Elsevier: Amsterdam, The Netherlands, 1990; pp. 315-322.

31. Vilgalys, R.; Hester, M. Rapid genetic identification and mapping of enzymatically amplified ribosomal DNA from several Cryptococcus species. J. Bacteriol. 1990, 172, 4238-4246. [CrossRef] [PubMed]

32. Hyde, K.D.; Norphanphoun, C.; Abreu, V.P.; Bazzicalupo, A.; Chethana, K.W.T.; Clericuzio, M.; Dayarathne, M.C.; Dissanayake, A.J.; Ekanayaka, A.H.; He, M.-Q.; et al. Fungal diversity notes 603-708: Taxonomic and phylogenetic notes on genera and species. Fungal Divers. 2017, 87, 1-235. [CrossRef]

33. Katoh, K.; Standley, D.M. MAFFT multiple sequence alignment software version 7: Improvements in performance and usability. Mol. Biol. Evol. 2013, 30, 772-780. [CrossRef] [PubMed]

34. Sudhir, K.; Glen, S.; Koichiro, T. Mega7: Molecular evolutionary genetics analysis version 7.0 for bigger datasets. Mol. Biol. Evol. 2016, 33, 1870-1874.

35. Kalyaanamoorthy, S.; Minh, B.Q.; Wong, T.; Von Haeseler, A.; Jermiin, L.S. ModelFinder: Fast model selection for accurate phylogenetic estimates. Nat. Methods 2017, 14, 587-589. [CrossRef] [PubMed]

36. Nguyen, L.-T.; Schmidt, H.; Von Haeseler, A.; Minh, B.Q. IQ-TREE: A Fast and Effective Stochastic Algorithm for Estimating Maximum-Likelihood Phylogenies. Mol. Biol. Evol. 2015, 32, 268-274. [CrossRef]

37. Stamatakis, A. Raxml-vi-hpc: Maximum likelihood-based phylogenetic analyses with thousands of taxa and mixed models. Bioinformatics 2006, 22, 2688-2690. [CrossRef]

38. Ronquist, F.; Teslenko, M.; Van Der Mark, P.; Ayres, D.L.; Darling, A.; Hoehna, S.; Larget, B.; Liu, L.; Suchard, M.A.; Huelsenbeck, J.P. MrBayes 3.2: Efficient Bayesian Phylogenetic Inference and Model Choice Across a Large Model Space. Syst. Biol. 2012, 61, 539-542. [CrossRef] [PubMed]

39. Floriani, M.; Vizzini, A. Calocybe pilosella sp. nov., a distinctive new lyophylloid agaric collected near Trento (Italy). Studi Trentini di Scienze Naturali 2016, 95, 17-24.

40. Fries, E.M. Systema Mycologicum I: i-vii; Ex Officina Berlingiana: Lund, Sweden; Greifswald, Germany, 1821.

41. Singer, R. Das System der Agaricales. III. Annales Mycologici 1943, 41, 1-189.

42. Singer, R. New and interesting species of Basidiomycetes. II. Pap. Mich. Acad. Sci. 1948, 32, 103-150.

43. Redhead, S.A.; Singer, R. On Calocybe names. Mycotaxon 1978, 6, 500-502.

44. Singer, R. Keys for the identification of the species of Agaricales I. Sydowia 1978, 30, 192-279. 